\title{
MERAIH LOYALITAS PELANGGAN DENGAN ETIKA KOMUNIKASI SALES DAN CUSTOMER RELATIONSHIP MANAGEMENT
}

(Studi Pada Rumah Batik Danar Hadi Semarang)

\author{
Oleh : \\ IWAN PRASETYO ${ }^{1}$ \\ TRI ENDANG YANI ${ }^{2}$ \\ ${ }^{1,2}$ Program Studi Manajemen Fakultas Ekonomi Universitas Semarang \\ J1. Soekarno-Hatta ,Tologosari Kulon, Kec. Pedurungan. \\ Kota Semarang, Jawa Tengah \\ iwan.usm@yahoo.com \\ Hp. 085771454621
}

\begin{abstract}
ABSTRAK
Tujuan dari penelitian ini untuk mengetahui : 1) Pengaruh etika komunikasi terhadap loyalitas pelanggan; 2) Pengaruh customer relationship management terhadap loyalitas pelanggan; 3) Kepuasan pelanggan terhadap loyalitas pelanggan. Dan seberapa besar pengaruh dari variabel etika komunikasi, customer relationship management dan kepuasan pelanggan terhadap loyalitas. Objek penelitian pada Rumah Batik Danar Hadi pada pelanggan metode purposive sampling sebanyak 96 responden. Pada penelitian ini menggunakan data primer yang bersumber dari jawaban responden terhadap kuesioner yang disebarkan yang berisi pertanyaan yang mewakili indikator setiap variabel dan data analisis menggunakan regresi linier. Hasil dari penelitian yang telah dilakukan dimana etika komunikasi, customer relationship management, kepuasan pelanggan berpengaruh positif signifikan terhadap variabel loyalitas pelanggan. Dari hasil uji regresi dapat ditarik kesimpulan jika ketiga variabel diatas yaitu etika komunikasi, customer relationship management dan kepuasan pelanggan sangatlah diperlukan untuk dapat meningkatkan loyalitas pelanggan.
\end{abstract}

Kata Kunci : Etika Komunikasi, Customer Relathionship Management, Kepuasan Pelanggan dan Loyalitas Pelanggan

\section{ABSTRACT}

The purpose of this study is to find out: 1) The effect of communication ethics on customer loyalty; 2) The effect of customer relationship management on customer loyalty; 3) Customer satisfaction with customer loyalty. And how much influence the variables of communication ethics, customer relationship management and customer satisfaction on loyalty. The object of research at the Danar Hadi Batik House was on the purposive sampling method customers of 96 respondents. In this study using primary data sourced from respondents' answers to questionnaires distributed containing questions that represent indicators of each variable and data analysis using linear regression. The results of research that has been done where communication ethics, customer relationship management, customer satisfaction has a significant positive effect on customer loyalty 
variables. From the regression test results it can be concluded if the three variables above namely communication ethics, customer relationship management and customer satisfaction are needed to be able to increase customer loyalty.

Keywords: Communication Ethics, Customer Relationship Management, Customer Satisfaction and Customer Loyalty

\section{PENDAHULUAN}

\section{Latar Belakang Masalah}

Perkembangan dunia usaha dewasa ini telah diwarnai oleh persaingan yang semakin ketat. Hal ini diakibatkan karena adanya arus globalisasi yang semakin terbuka lebar bagi setiap pelaku bisnis. Timbulnya persaingan yang sangat ketat tersebut menyebabkan kalangan usaha memanfaatkan hubungan yang kuat antara perusahaan dengan pelanggan untuk mendapatkan informasi tentang bagaimana cara terbaik untuk melayani pelanggan dan menjaga agar tidak berpindah ke merek lain. Meningkatnya intensitas persaingan dan jumlah pesaing menuntut perusahaan untuk selalu memperhatikan kebutuhan dan keinginan konsumen serta berusaha memenuhi harapan konsumen dengan cara memberikan pelayanan kepada konsumen yang lebih memuaskan dari pada yang dilakukan oleh pesaing usaha yang sejenis.

Pesatnya perkembangan tehnologi saat ini dalam bidang fashion batik khususnya menyebabkan kemudahan konsumen untuk memilihi secara bebas, oleh karena itu kesempatan perusahaan untuk mendapatka loyalitas customer menjadi sangat kecil. Menurut Hurriyati (2008) Loyalitas merupakan Adanya keterkaitan komitmen yang dimiliki antara pelanggan dengan perusahaan untuk kembali melakukan pembelian di masa yang akan datang. Griffin (2008), loyalitas customer merupakan sebuah perilaku yang ditunjukan customer dengan pembelian rutin, berdasarkan pada unit dalam pengambilan keputusan, Kotler \& Armstrong (2011) Kesetiaan seseorang akan suatu produk, Tjiptono (2007) Customer loyal akan cenderung membeli produk yang sama walaupun terdapat banyak pilihan alternatif lainnya. Dari beberapa teori diatas dapat ditarik kesimpulan jika loyalitas merupakan sikap yang positif yang diberikan cutomer kepada perusahaan terhadapa produk ataupun jasa sehingga customer tersebut akan datang untuk membeli ataupun memakai produk dan jasa dari perusahaan tersebut.

Fenomena bisnis yang terjadi saat ini pada PT Danar Hadi sedang mengalami penurunan loyalitas pelanggan, dimana penurunan dapat dilihat dari penggunaan member Batik Danar Hadi yang menurun dari tahun 2017 ke 2018. Penurunan pengguna member dialami seluruh category member yang ada baik reguler, silver dan gold dengan dengan total sebesar $42 \%$, selain penurunan pada pengguna member tejadi penurunan rata-rata transaksi sebesar $6 \%$ dari tahun sebelumnya 
sehingga dapat ditarik kesimpulan jika kondisi yang dialami Rumah Batik Danar Hadi saat ini adalah penurunan loyalitas.

Etika karyawan dalam berkomunikasi sangatlah diperlukan untuk dapat meningkatkan hubungan yang baik dengan pelanggan. "Etika komunikasi yang berlaku dalam perusahaan berhubungan dengan dapat dipercaya, fair, tidak memihak, menghargai orang lain, dan mempertimbangkan pengaruh suatu ucapan atau tindakan terhadap orang lain (Sutrisna, 2007)”. Pelayanan yang baik akan memberikan kepuasan kepada pelanggan dan dapat mempertahankan pelanggan yang sudah ada untuk terus membeli, mengkonsumsi, dan akan selalu setia terhadap produk yang di tawarkan diperusahaan tersebut, dengan banyaknya kepuasan dan kesetiaan pelanggan yang ada akan memberikan dampak positif kepada perusahaan untuk dapat menarik pelanggan yang baru untuk mencobanya Untuk mempertahankan loyalitas pelanggan diperlukan usaha untuk menjaga hubungan baik antara pelanggan lama atau dikenal dengan customer relationship management. Kotler \& Amstrong (2008) proses membangun dan menjaga hubungan terhadap customer yang menguntungkan dengan menghantarkan nilai dan kepuasan pelanggan, Lupiyoadi (2009) Menarik dan mempertahankan hubungan pelanggan melalui meningkatkan hubungan. Alma (2010) Suatu proses mendapatkan, mempertahankan, meningkatkan hubungan yang menguntungkan, Lovelock \& Wirtz (2011) suatu sistem implementasi untuk meningkatkan, Kotler \& Armstrong (2012) proses maintanance profit dari customer untuk menciptakan nilai dan kepuasan, Kotler dan Keller (2009) proses mengelola informasi rinci tentang pelanggan perorangan untuk memaksimalkan loyalitas.

Dalam persaingan bisnis saat ini penilai positif yang diberikan customer kepada perusahaan sangatlah penting, hal tersebut menandakan jika customer yang bersangkutan merasa puas atas apa yang mereka harapkan dari perusahaan dapat tercapai. Menurut Kotler dan Keller (2009) perasaan pelanggan yang dihasilkan dari membandingkan kinerja yang dipersepsikan dengan ekspektasi pelanggan, mengevaluasi akan sesuai suatu produk atau jasa dengan yang diharapkan oleh konsumen Schiffman dan Kanuk (2007). Memberi kepuasan kepada konsumen adalah hal yang sangat penting bagi perusahaan. Karena kepuasan yang tinggi akan berdampak pada loyalitas konsumen menurut Tjiptono (2008). Berdasarkan beberapa pejelasan diatas dapat disimpulkan jika kepuasan customer sangatlah penting dalam mempertahankan loyalitas terhadap perusahaan.

Dari Fenomena diatas peneliti sangat tertarik untuk melakukan penelitian mengenai sebab penurunan loyalitas customer pada Rumah Batik Danar Hasi Semarang. Berdasarkan latar belakang yang telah diuraikan diatas maka peneliti tertarik mengambil Judul Penelitian "Meraih Loyalitas Pelanggan Dengan Etika Komunikasi Sales Dan Customer Relationship Management "Study Pada Rumah Batik Danar Hadi Semarang”. Dengan dilakukannya penelitian mengenai loyalitas ini 
diharapkan dapat membantu Rumah Batik Danar Hadi untuk memperhatikan kembali mengenai loyalitas pelanggan dan dapat menyususn strategi agar perusahaan dapat meningkatkan eksistensi dalam persainagn usaha yang semakin ketat.

\section{Rumusan Masalah}

Dapat ditarik kesimpulan berdasarkan latar belakang yang telah diuraikan di atas menjelaskan bahwa fenomena bisnis yang terjadi penurunan loyalitas customer pada Rumah Batik Danar Hadi Semarang baik dilihat dari segi value ataupun dilihat dari segi jumlah transaksi pada member tersebut dan rata-rata transaksi. Sehingga Perumusan masalah yang dapat diangkat dalam penelitian ini adalah bagaimana Rumah Batik Danar Hadi Semarang dapat meningkatkan penjualan melalui peningkatan loyalitas pelanggan yang selama ini mengalami penurunan.

\section{Tujuan Penelitian}

Dilihat dari latar belakang masalah dan rumusan masalah penelitian yang terjadi pada Rumah Batik Danar Hadi, maka tujuan penelitian ini adalah guna menganalisa Etika Komunikasi, Customer Relationship Management, Kepuasan Customer yang berpengaruh terhadap Loyalitas Pelanggan pada Rumah Batik Danar Hadi Semarang.

\section{Kajian Pustaka}

\section{Etika Komunikasi.}

Etika komunikasi menurut Dewi (2007), secara operasional didefinisikan sebagai tingkat di mana isi komunikasi dapat diterima dan dipahami oleh pihak lain yang terlibat dalam proses komunikasi tersebut. Hal ini dapat dikatakan sarana terbaik bagi konsumen untuk mencapai kualitas adalah melalui komunikasi antara penyedia jasa dengan penerima jasa itu. Artinya, semakin tinggi kualitas komunikasi antara perusahaan dengan pelanggan, maka semakin tinggi pula kualitas jasa yang diberikan. Kualitas komunikasi karyawan menjadi hal yang sangat penting karena kualitas komunikasi karyawan merupakan cerminan dari kualitas komunikasi perusahaan kepada pelanggannya.

Selain itu Arni (2005) berpendapat bahwa komunikasi yang efektif harus memperhatikan: (1) pengirim (sumber-sumber), (2) pesan, (3) saluran, (4) penerima, dan (5) umpan balik. Kualitas komunikasi memiliki dimensi, Jones (2005) menyatakan kualitas komunikasi memiliki dua faktor laten yaitu kualitas komunikasi inpersonal dan interpersonal, dengan indikator antara lain: excellent communication, provide superior information its communication, accuracy, easy, dan communicate well. Selain itu menurut Arni (2005), menyatakan bahwa: Indikator yang digunakan juga menggunakan dua dimensi utama komunikasi yaitu kualitas komunikasi verbal (intonasi, logat, gaya bicara, kefasihan bahasa) dan non-verbal (ekspresi dan gerakan anggota tubuh ketika berkomunikasi). kepada pihak lain secara efektif dan efisien, sehingga tujuanpenyampaian pesan- 
pesan bisnis dapat tercapai. Komunikasi bisnis tersebut berkaitan erat dengan komunikasi pemasaran (marketing communication). Komunikasi pemasaran (Shim, 2003) merepresentasikan gabungan semua unsur dalam bauran pemasaran merek, yang memfasilitasi terjadinya pertukaran dengan menciptakan suatu arti yang disebarluaskan kepada pelanggan atau kliennya. Komunikasi pemasaran dapat berupa pakaian yang dikenakan oleh seorang tenaga penjual, katalog harga, produk dan jasa layanan, serta kantor perusahaan. Dari sudut pandang manajer pemasaran, komunikasi pemasaran memiliki tujuan-tujuan sebagai berikut (Peter \& Olson, 2000) konsumen harus memiliki kebutuhan yang disadari akan suatu kategori produk atau bentuk produk; konsumen harus sadar akan merek; konsumen harus memiliki pemahaman terhadap merek yang positif; konsumen harus memiliki keinginan untuk membeli merek tertentu; konsumen harus melakukan berbagai macam perilaku untuk membeli merek tertentu. Komunikasi antarpribadi (interpersonal communication) adalah komunikasi antara orangorang secara tatap muka, yang memungkinkan setiap orang menangkap reaksi orang lain secara langsung, baik secara verbal maupun nonverbal. Bentuk khusus dari komunikasi antarpribadi adalah komunikasi diadik yang melibatkan hanya dua orang. Ciri-ciri komunikasi diadik adalah pihak-pihak yang berkomunikasi berada dalam jarak yang dekat dan pihak-pihak yang berkomunikasi mengirim dan menerima pesan secara simultan dan spontan, baik secara verbal maupun nonverbal.

\section{Customer Relationship Management}

Customer Relationship management adalah proses pengelolaan data customer secara rinci untuk memaksimalkan kesetiaan pelanggan Kotler dan Keller (2007), Alma (2010) Suatu proses mendapatkan, mempertahankan, meningkatkan hubungan yang menguntungkan, Lovelock \& Wirtz (2011) suatu sistem implementasi untuk meningkatkan, Kotler \& Armstrong (2012) proses maintanance profit dari customer untuk menciptakan nilai dan kepuasan, Kotler dan Keller (2009) proses mengelola informasi rinci tentang pelanggan perorangan untuk memaksimalkan loyalitas. Dari beberapa penjelasan diatas dapat ditarik kesimpulan Customer relationship management merupakan suatu proses pengelolaan customer secara individual dan terperinci guna untuk mencapai kesetiaan customer terhadap perusahaan.

Menurut Febrianingtyas (2013) menjelaskan bahwa ada empat faktor yang mempengaruhi Customer Relationship Management antara lain :

1. Komitmen.

Adalah suatu orientasi customer jangka panjang terhaap hubungan berdasarkan pada ikatan emosional dan adanya keinginan untuk menjaga hubungan agartetap menghasilkan profit. loyalitas pelanggan adalah komitmen pelanggan terhadap suatu merek, toko, atau pemasok berdasarkan sikap yang sangat positif dan tercermin dalam pembelian ulang yang konsisten. 


\section{Komunikasi.}

Adalaha karakteristik dari sebuah hubungan yang berjalan dengan baik. Lombard dan Plessis (2012) mengemukakan bahwa pengumpulan informasi dari pelanggan dapat dilakukan saat terjadi percakapan atau tanya jawab secara langsung, berfokus pada kelompok pelanggan tertentu, dan mengobservasi atau mencari tahu mengenai pembelian yang dilakukan oleh pelanggan.

3. Kualitas Pelayanan.

Kotler dan Keller (2009) menjelaskan bahwa kualitas merupakan kunci untuk menciptakan nilai dan kepuasan pelanggan. Kualitas pelayanan jasa angkutan terdiri dari 5 faktor, yaitu frekuensi, pelayanan baku, kenyamanan, ketepatan, keamanan.

\section{Kepuasan Pelanggan}

Kepuasan keseluruhan (overall satisfaction) didefinisikan sebagai pernyataan efektif tentang reaksi emosional terhadap pengalaman atas produk atau layanan yang dipengaruhi oleh kepuasan konsumen terhadap produk tersebut (attribute satisfaction) dan informasi yang digunakan untuk memilih produk (information satisfaction). Kepuasan palanggan berhubungan erat dengan loyalitas pelanggan, dimana pelanggan yang terpuaskan akan menjadi pelanggan yang loyal. Kepuasan pelanggan akan tercapai apabila harapan sesuai dengan kenyataan yang diterima. Kepuasan pelanggan tinggi apabila nilai yang dirasakan melebihi harapan pelanggan. Penerimaan produk dengan kualitas yang lebih tinggi akan mendapatkan tingkat kepuasan yang lebih tinggi daripada penerimaan produk dengan kualitas yang lebih rendah.

Menurut (Tjiptono, 2008) mengungkapkan bahwa dalam mengevaluasi kepuasan terhadap produk, jasa, atau perusahaan tertentu, konsumen umumnya mengacu pada berbagai faktor atau dimensi. Faktor yang sering digunakan dalam mengevaluasi kepuasan terhadap suatu produk antara lain meliputi :

1. Kinerja (performance) karakteristik operasi pokok dari produk inti (core product) yang dibeli.

2. Ciri-ciri keistimewaan tambah (features) yaitu karakteristik sekunderatau pelengkap.

3. Keandalan (reliability) yaitu kemungkinan kecil akan mengalamikerusakan atau gagal dipakai.

4. Kesesuaian dengan spesifikasi (conformance to specifications) yaitu sejauh mana karakteristik desain dan operasi memenuhi standar-standar yang telah ditetapkan sebelumnya.

5. Daya tahan (durability) berkaitan dengan berapa lama produk tersebutdapat terus digunakan. Dimensi ini mencakup umur teknis maupun umur ekonomis penggunaan.

6. Serviceability meliputi kecepatan, kompetensi, kenyamanan, mudah diperbaiki serta penanganan keluhan yang memuaskan. Pelayanan yangdiberikan tidak hanya sebatas sebelum penjualan, tetapi juga selama proses penjualan hingga purna jual,yang mencakup pelayanan reparasi dan ketersediaan komponen yang dibutuhkan. 
7. Estetika, yaitu daya tarik produk terhadap panca indera, misalnya bentuk fisik yang menarik, model/ desain, warna, dan sebagainya.

8. Kualitas yang dipersepsikan (perceived quality), yaitu citra dan Reputasi produk serta tanggung jawab perusahaan terhadapnya.

\section{Loyalitas Pelanggan}

Menurut Lupiyoadi (2009) prefensi customer terhadap orang lain dan pembelian secara actual di lain waktu, Rasyid (2017) suatu kesetiaan customer kepada suatu produk atau perusahaan dan dengan senang hati akan berbagi dengan orang lain tentang pengalaman dan pengetahuan mereka serta adanya rasa bangga tersendiri mereka menggunakan produk atau jasa dari perusahaan itu. Merupakan hubungan yang kuat antara customer dengan perusahaan Chang (2013), suatu konsep penting dalam sebuah manajemen pelayanan Thaicon (2014), Arshad (2016) komitmen customer terhadap suatu produk, sejalan dengan itu jika customer sudah merasa tidak puas maka mereka akan mencari produk pengganti Amin (2011) Kaur (2012). Berdasarkan beberapa teori yang dikemukanan bisa disimpulkan jika loyalitas customer merupakan suatu sikap baik yang diberikan kepada perusahaan atas dasar pelayanan yang diberikan perusahaan sehingga akan menimbulkan rasa setia terhadap perusahaan dan akan memberikan kesan positif perusahaan kepada orang lain.

\section{METODE PENELITIAN}

\section{Variabel Penelitian}

1. Variabel Independen atau Variabel Bebas (X) adalah Variabel yang mempengaruhi variabel dependen, dimana pengaruh yang dihasilkan bisa berpengaruh positif ataupun negatif. Variabel independen pada penelitian ini adalah etika komunikasi, customer relationship management dan kepuasan pelanggan.

2. Variabel Dependen atau Variabel Tetap adalah Variabel yang dipengaruhi oleh variabel independen, dimana variabel dependen ini merupakan pokok dari permasalahan dalam penelitian. Dalam penelitian ini variabel dependen nya adalah loyalitas pelanggan.

\section{Populasi dan Sampel}

Populasi dalam penelitian ini adalahseluruh pelanggan Rumah Batik Danar Hadi Semarang. Metode pengambilan sampel yang digunakan dalam penelitian ini adalah Purposive Sampling, teknik ini dipilih karena peneliti telah memahami bahwa informasi yang dibutuhkan dapat diperoleh dari satu kelompok sasaran tertentu yang mampu memberikan informasi mengenai alasan pembelian secara berulah Pda Rumah Batik Danar Semarang Dimana pada Teknik ini mengedepankan beberapa kriteria sampel. Kriteria sampel dalam penelitian ini . Responden memiliki usia diatas 18 tahun karena diusia tersebut konsumen mulai bisa mengambil keputusan dengan baik dan tidak mudah 
dipengaruhi oleh produk lain. Serta responden sudah menjadi member ataupun pelanggan reguler batik Danar Hadi, karena member atau pelanggan reguler, mereka pasti belanja lebih dari 1 kali dalam setahun pada store Batik Danar Hadi. Dalam penelitian ini jumlah sampel yang diambil sejumlah 96 yang diharapkan berimbang jumlah respondennya. Jenis Data dan Sumber Data dalam penelitian ini adalah Data primer dan Data Sekunder Metode pengumpulan data dalam penelitian ini adalah sebagai berikut : Observasi, Questioner, Wawancara dan Studi pustaka.Metode Analisis Data dalam penelitian ini adalah Analisis Deskriptif dan analisis Kuantitatif.

\section{HASIL PENELITIAN DAN PEMBAHASAN}

\section{Hasil Penelitian}

\section{Uji Validitas.}

Berdasarkan tabel hasil uji validitas yang telah dilakukan sebelumnya didapatkan nilai bahwa semua item indikator pada setiap variabel penelitian Etika Komunikasi $\left(\mathrm{X}_{1}\right)$, Customer relationship management $\left(\mathrm{X}_{2}\right)$, Kepuasan Pelanggan $\left(\mathrm{X}_{3}\right)$ dan Loyalitas pelanggan $(\mathrm{Y})$ dinyatakan valid karena hasil dari koreasi antara hasil jawaban responden setiap item indikator dengan skor total di dapat hasil yang signifikan, yaitu nilai rhitung > rtabel.

\section{Uji Realibilitas.}

Hasil Uji reabilitas didapatkan nilai Cronbach's Alpha pada setiap variabel penelitian Etika Komunikasi $(0,784)$, Customer relationship management $(0,926)$, Kepuasan Pelanggan $(0,700)$ dan Loyalitas pelanggan $(0,802)$. Dapat dilihat jika hasil dari uji reliablitas memiliki Cronbach's Alpha diatas 0,60 dinyatakan reliabel atau dapat dipercaya/handal, yang berarti apabila data tersebut dipergunakan pada obyek penelitian yang berbeda, pada waktu yang berbeda akan memberikan hasil yang sama dengan hasil yang diperoleh pada penelitian ini.

\section{Uji Asusmsi Klasik.}

Uji asumsi klasik dilakukan terhadap data yang digunakan untuk analisis regresi berganda. Uji asumsi klasik terdiri dari uji normalitas, uji multikolinearitas dan uji heteroskedastisitas.

\section{Uji Normalitas}

Berdasarkan hasil uji normalitas yang telah diujikan dengan menggunakan Uji One Sample Kolmogorov Smirnov Test didapatkan nilai residual Asymp Sig (2-tailed) sebesar 0,246 > 0,05. Hal itu berarti data terdistribusi secara normal. Oleh karena itu dapat disimpulkan bahwa data yang digunakan dalam penelitian ini berdistribusi normal. 


\section{Uji Multikolorinitas}

Pada hasil pengujian multikolinearitas model regresi menunjukkan bahwa antar variabel Etika Komunikasi $\left(\mathrm{X}_{1}\right)$, Customer Relationship Management $\left(\mathrm{X}_{2}\right)$, Kepuasan Pelanggan $\left(\mathrm{X}_{3}\right)$, dan Loyalitas Pelanggan (Y) semuanya tidak terjadi multiko-linearitas, karena nilai tolerance masingmasing variabel independen berada di atas 0,1 dan nilai VIF masing-masing variabel independen berada di bawah 10 .

\section{Uji Heteroskedastisitas.}

Dari hasil pengujian hereroskedastisitas menggunakan uji glejser dimana dari hasil uji gletser probabilitas semua variabel memiliki nilai signifikansi diatas tingkat kepercayaan 5\% atau 0,05 pada semua variabel. Sehingga model regresi layak untuk digunakan dalam melakukan pengujian

\section{Analisis Regresi Berganda.}

Analisis regresi linier berganda digunakan untuk melihat pengaruh antara variable Etika Komunikasi, Customer Relationship Management, Kepuasan Pelanggan terhadap Loyalitas Pelanggan. Hasil analisis regresi berganda dengan menggunakan program SPSS adalah sebagai berikut :

Tabel 1. Koefisiensi Regresi Linier Berganda

Coefficients $^{\mathrm{a}}$

\begin{tabular}{|c|c|c|c|c|c|c|c|}
\hline \multirow[t]{2}{*}{ Model } & \multicolumn{2}{|c|}{$\begin{array}{l}\text { Unstandardized } \\
\text { Coefficients }\end{array}$} & \multirow{2}{*}{$\begin{array}{c}\begin{array}{c}\text { Standardized } \\
\text { Coefficients }\end{array} \\
\text { Beta }\end{array}$} & \multirow[b]{2}{*}{$\mathbf{t}$} & \multirow[b]{2}{*}{ Sig. } & \multicolumn{2}{|c|}{ Collinearity Statistics } \\
\hline & B & Std. Error & & & & Tolerance & VIF \\
\hline (Constant) & 2,068 & 2,026 & & 1,021 &, 310 & & \\
\hline $\mathrm{x} 1$ &, 234 &, 107 &, 177 & 2,181 &, 032 & ,784 & 1,276 \\
\hline $\mathrm{x} 2$ & ,362 & 055 & ,539 & 6,583 &, 000 & ,766 & 1,305 \\
\hline $\mathrm{x} 3$ & , 178 & 076 &, 184 & 2,354 &, 021 &, 845 & 1,184 \\
\hline
\end{tabular}

a. Dependent Variable: y

Persamaan regresi dari tabel diatas

Adalah $\mathrm{Y}=0,177\left(\mathrm{X}_{1}\right)+0,539\left(\mathrm{X}_{2}\right)+0,184\left(\mathrm{X}_{3}\right)$

Persamaan linier berganda yang dapat diartikan

1. Dari hasil koefisien regresi didapatkan nilai positif sebesar 0,177 untuk variabel etika komunikasi. Sehingga dapat disimpulkan dengan ditingkatkannya variabel etika komunikasi maka variabel loyalitas pelanggan akan mengalami peningkatan dengan asumsi variabel lain akan tetap.

2. Dari hasil koefisien regresi didapatkan nilai positif sebesar 0,539 untuk variabel customer relatinship management. Sehingga dapat disimpulkan dengan ditingkatkannya variabel customer relatinship management maka variabel loyalitas pelanggan akan mengalami peningkatan dengan asumsi variabel lain akan tetap. 
3. Dari hasil koefisien regresi didapatkan nilai positif sebesar 0,184 untuk variabel kepuasan pelanggan. Sehingga dapat disimpulkan dengan ditingkatkan nya variabel kepuasan pelanggan maka variabel loyalitas pelanggan akan mengalami peningkatan dengan asumsi variabel lain akan tetap.

\section{Pengujian Hipotesis}

Tabel 2. Koefisiensi Regresi Linier Berganda Coefficients $^{\mathrm{a}}$

\begin{tabular}{|c|c|c|c|c|c|c|c|c|}
\hline \multirow{2}{*}{\multicolumn{2}{|c|}{ Model }} & \multicolumn{2}{|c|}{$\begin{array}{c}\text { Unstandardized } \\
\text { Coefficients } \\
\end{array}$} & \multirow{2}{*}{$\begin{array}{c}\begin{array}{c}\text { Standardized } \\
\text { Coefficients }\end{array} \\
\text { Beta } \\
\end{array}$} & \multirow[b]{2}{*}{$\mathbf{t}$} & \multirow[b]{2}{*}{ Sig. } & \multicolumn{2}{|c|}{ Collinearity Statistics } \\
\hline & & B & Std. Error & & & & Tolerance & VIF \\
\hline \multirow[t]{4}{*}{1} & (Constant) & 2,068 & 2,026 & & 1,021 &, 310 & & \\
\hline & $\mathrm{x} 1$ & 234 &, 107 &, 177 & 2,181 & 032 & ,784 & 1,276 \\
\hline & $\mathrm{x} 2$ & ,362 &, 055 & ,539 & 6,583 &, 000 & ,766 & 1,305 \\
\hline & $\mathrm{x} 3$ &, 178 &, 076 & 184 & 2,354 & 021 & ,845 & 1,184 \\
\hline
\end{tabular}

a. Dependent Variable: $y$

Hipotesis 1 : Pengaruh Etika Komunikasi Terhadap Loyalitas Pelanggan Pada Rumah Batik Danar Hadi Semarang.

Dari uji statistik t diatas didapatkan nilai signifikansi sebesar 0,032 dimana nilai tersebut lebih kecil 0,05 . Yang berarti hipotesis pertama pada penelitian ini yaitu variabel etika komunikasi diterima dan berpengaruh secara signifikan terhadap loyalitas pelanggan.

Hipotesis 2 : Pengaruh Customer Relationship Management Terhadap Loyalitas Pelanggan Pada Rumah Batik Danar Hadi Semarang.

Dari uji statistik t diatas didapatkan nilai signifikansi sebesar 0,00 dimana nilai tersebut lebih kecil 0,05. Yang berarti hipotesis kedua pada penelitian ini yaitu variabel customer relationship management diterima dan berpengaruh secara signifikan terhadap loyalitas pelanggan

Hipotesis 3 : Pengaruh Kepuasan Pelanggan Terhadap Loyalitas Pelanggan Pada Rumah Batik Danar Hadi Semarang

Dari uji statistik t diatas didapatkan nilai signifikansi sebesar 0,021 dimana nilai tersebut lebih kecil 0,05. Yang berarti hipotesis ketiga pada penelitian ini yaitu variabel kepuasan pelanggan diterima dan berpengaruh secara signifikan terhadap loyalitas pelanggan.

\section{Uji Koefisien Determinasi}

Dari tabel diatas dapat diketahui bahwa diperoleh Adjust R Square 0,511. yang artinya ketiga variabel pada penelitian ini yaitu Etika Komunikasi, Customer Relationship Management, Kepuasan Pelanggan hanya mampu mempengaruhi variabel Loyalitas Pelanggan sebesar 51\% dan variabel lain yang tidak diteliti pada oleh peneli mampu mempengaruhi sebesar $49 \%$. 


\section{Uji Statistik F}

Tabel 3. Uji Statistik F

\begin{tabular}{|l|l|r|r|r|r|r|}
\hline \multicolumn{7}{|c|}{ ANOVAb } \\
\hline \multicolumn{2}{|l|}{ Model } & Sum of Squares & \multicolumn{1}{c|}{ Df } & Mean Square & \multicolumn{1}{l|}{ F } & \multicolumn{1}{c|}{ Sig. } \\
\hline \multirow{2}{*}{1} & Regression & 423,592 & 3 & 141,197 & 34,152 & \multirow{2}{*}{000} \\
\cline { 2 - 7 } & Residual & 380,366 & 92 & 4,134 & & \\
\cline { 2 - 7 } & Total & 803,958 & 95 & & & \\
\hline
\end{tabular}

Berdasarkan tabel diatas $\mathrm{F}$ hitung sebesar 34,152 dan nilai probabilitas signifikan sebesar 0,000 dibawah nilai kritis 0,05 atau $5 \%$. Hal ini berarti bahwa variabel independen berpengaruh terhadap variabel dependen.

\section{Pembahasan}

Pada penelitian ini dilatar belakangi adanya penurunan penggunaan member pada Rumah Batik Danar Hadi Semarang sehingga dari penurunan pengguna member tersebut sedikit banyak mempengaruhi penurunan pendapatan penjualan. Dimana penelitian mengambil sampel sebanyak 96 koresponden pada bagian customer. Sedangkan instrumen berupa kuesioner yang digunakan peneliti untuk pengumpulan data penelitian dan tehnik pengolahan data menggunakan model analisis regresi linier berganda untuk membuktikan penelitian tersebut.

1. Pada Hipotesis 1 menyatakan "Etika Komunikasi berpengaruh positif terhadap Loyalitas Pelanggan”. Dimana hasil pengujian regresi didapatkan hasil 0,177 dan Sig 0,032<0,05. sehingga Ho ditolak dan Ha diterima, yang berarti Etika Komunikasi $\left(\mathrm{X}_{1}\right)$ berpengaruh positif dan signifikan terhadap Loyalitas Pelanggan (Y) pada Rumah Batik Danar Hadi Semarang. "Signifikan" mengandung arti bahwa Etika Komunikasi memang mempunyai pengaruh yang bermakna/signifikan terhadap Loyalitas Pelanggan, sehingga dapat disimpulkan bahwa Etika Komunikasi merupakan salah satu faktor penentu loyalitas pelanggan pada Rumah Batik Danar Hadi. Dimana Pelanggan beranggapan jika etika dalam berkomunikasi karyawan terhadap pelanggannya itu baik, pelanggan berharap karyawan selalu bersikap sopan, tutur kata yang baik didalam melakukan pelayanan terhadap pelanggan, serta selalu memberikan arahan yang bersifat positif teradap pelanggan. Selain itu dari kuesioner yang telah dibagikan kepada responden jika mereka setuju jika Etika komunikasi akan berdampak pada loyalitas pelanggan.

Koefisien beta (koefisien regresi) variabel Etika Komunikasi adalah 0,177 atau 17,7 \% . Dimana Koefisien regresi ini merepresentasikan kekuatan pengaruh variabel Etika Komunikasi terhadap variabel Loyalitas Pelanggan. Arti dari koefisien regresi 17,8\% tersebut adalah jika variabel bebas yang lain dianggap tetap (tidak ada perubahan) dan variabel Etika komunikasi 
ditingkatkan sebesar $1 \%$ daripada sebelumnya, maka akan diikuti oleh kenaikan variabel loyalitas pelanggan sebesar $17,7 \%$.

2. Pada Hipotesis 2 menyatakan "Customer Relationship Management berpengaruh positif terhadap Loyalitas Pelanggan”. Dimana hasil pengujian regresi didapatkan hasil 0,539 dan Sig 0,000< 0,05. sehingga Ho ditolak dan Ha diterima, yang berarti Customer Relationship Management $\left(\mathrm{X}_{2}\right)$ berpengaruh positif dan signifikan terhadap Loyalitas Pelanggan (Y) pada Rumah Batik Danar Hadi Semarang.

"Signifikan" mengandung arti bahwa Customer Relationship Management memang mempunyai pengaruh yang bermakna/signifikan terhadap Loyalitas Pelanggan, sehingga dapat disimpulkan bahwa Customer relationship Management merupakan salah satu faktor yang menjadi penentu loyalitas pelanggan pada Rumah Batik Danar Hadi. Dimana Pelanggan beranggapan jika perusahaan selalu menjaga hubungan baik terhadap pelanggan, selalu mmberikan pelayanan secara baik, dan memberikan potongan khusus kepada pelanggan reguler Batik Danar Hadi maka akan berdampak pada pelanggan yang semakin loyal terhadap perusahaan. Selain itu dari kuesioner yang telah dibagikan kepada responden jika mereka setuju pelanggan memberikan respon setuju sehingga dapat disimpulkan jika Customer Relationship Management akan mampu memberikan efek posistif pada loyalitasnya pelanggan.

Koefisien beta (koefisien regresi) variabel Customer Relationship Management adalah 0,539 atau 53,9\% . Dimana Koefisien regresi ini merepresentasikan kekuatan pengaruh variabel Customer Relationship Management terhadap variabel Loyalitas Pelanggan. Arti dari koefisien regresi 53,9\% tersebut adalah jika variabel bebas yang lain dianggap tetap (tidak ada perubahan) dan variabel Customer Relationship Management ditingkatkan sebesar 1\% daripada sebelumnya, maka akan diikuti oleh kenaikan variabel loyalitas pelanggan sebesar 53,9\%

3. Pada Hipotesis 3 menyatakan "Kepuasan Pelanggan berpengaruh positif terhadap Loyalitas Pelanggan". Dimana hasil pengujian regresi didapatkan hasil 0,184 dan Sig 0,021 < 0,05. sehingga Ho ditolak dan Ha diterima, yang berarti Kepuasan Pelanggan $\left(\mathrm{X}_{3}\right)$ berpengaruh positif dan signifikan terhadap Loyalitas Pelanggan (Y) pada Rumah Batik Danar Hadi Semarang.

Signifikan" mengandung arti bahwa Kepuasan Pelanggan memang mempunyai pengaruh yang bermakna/signifikan terhadap Loyalitas Pelanggan, sehingga dapat disimpulkan bahwa Kepuasan Pelanggan merupakan salah satu faktor yang menjadi penentu loyalitas pelanggan pada Rumah Batik Danar Hadi. Dengan memperhatikan kepuasan pelangggan dengan memberikan pelayanan yang baik terhadap pelanggan, memberikan kualitas yang terbaik serta keunikan akan motif dan ciri khas dari batik tersebut sehingga akan terciptanya kesan yang positif terhadap perusahaan sehingga akan berdampak pada loyalitas pelanggan. 
Koefisien beta (koefisien regresi) variabel Kepuasan Pelanggan adalah 0,184 atau 18,4\% . Dimana Koefisien regresi ini merepresentasikan kekuatan pengaruh variabel kepuasan pelanggan terhadap variabel Loyalitas Pelanggan. Arti dari koefisien regresi 18,4\% tersebut adalah jika variabel bebas yang lain dianggap tetap (tidak ada perubahan) dan variabel kepuasan pelanggan ditingkatkan sebesar $1 \%$ daripada sebelumnya, maka akan diikuti oleh kenaikan variabel loyalitas pelanggan sebesar $18,4 \%$

\section{PENUTUP}

\section{Simpulan}

Dapat ditarik simpulan untuk diambil keputusan yang telah dilakukan pada bab sebelum nya sebagai berikut :

a. Variabel etika komunikasi di dapatkan pengaruh secara positif signifikan terhadap veriabel loyalitas pelanggan. Artinya semakin baik etika komunikasi karyawan terhadap pelanggan maka pelanggan akan semakin loyal terhadap Batik Danar Hadi

b. Variabel customer relationship management didapatkan pengaruh positif tidak signifikan terhadap loyalitas pelanggan. Artinya semakin baik customer relationship management yang dilakukan perusahaan maka pelanggan akan semakin loyal tehadap Batik Danar Hadi.

c. Variabel kepuasan pelanggan didapatkan pengaruh secara positif signifikan terhadap loyalitas pelanggan. Artinya pelanggan yang semakin puas kepada Batik Danar Hadi maka pelangaan tersebut akan semakin loyal.

\section{Saran}

Berdasarkan hasil kuesioner yang dibagikan kepada responden dapat ditarik saran sebagai berikut :

1. Mengingat hasil dari pengujian etika komunikasi terhadap loyalitas pelanggan menghasilkan nilai positif signifikan. Maka diharapkan Rumah Batik Danar Hadi hendaknya membuat standar etika komunikasi dalam memberikan pelayanan kepada pelanggan. Sehingga dengan adanya etika dalam berkomunikasi terhadap pelanggan maka loyalitas pelanggan akan semakin meningkat terhadap Batik Danar Hadi.

2. Dari pengujian diatas didapatkan hasil positif signifikan customer realationship management terhadap loyalitas pelanggan. Oleh sebab itu diharapkan Rumah Batik Danar memperbaiki CRM yang sudah ada pada perusahaan, yaitu dengan menjalin kerjasama terhadap instansiyang ada untuk meningkatkan loyalitas pelanggan. 
3. Didapatkan hasil positif signifikan variabel kepuasan pelanggan terhadap loyalitas pelanggan. Secara keseluruhan pelanggan batik Danar Hadi sudah merasa puas sehingga indikator-indikator yang dapat meningkatkan kepuasan pelanggan perlu dipertahankan dan karyawan mampu meningkatkan pelayan terhadap customer sehingga akan tercipta kesan yang positif terhadap perusahaan

\section{DAFTAR PUSTAKA}

Alma, Buchari. 2010. Pengantar Bisnis. Penerbit Alfabeta Bandung

Arni, Muhammad. (2005). Komunikasi Organisasi. Jakarta : Bumi Aksar

Amin, M., Isa, Z., \& Fontain, R. (2011), "The role of customer satisfaction in enhancing customer loyalty in Malaysian Islamic banks”. The Service Industries Journal, 1519-32.

Arshad, T., Zahra, R. \& Draz, U. (2016), “Impact of Customer Satisfaction on Image , Trust, Loyalty and the Customer Switching Behavior in Conventional and Islamic Banking : Evidence from Pakistan" American Journal of Business and Society, Vol. 1, No. 3, 2016, pp. 154-165

Chang, C.-W., Tseng, T.-H. and Woodside, A.G. (2013), "Configural algorithms of patient satisfaction, participation in diagnostics, and treatment decisions influences on hospital loyalty". Journal of Services Marketing, Vol. 27 No. 2,pp. 91-103.

De Vito, J.A. (1997). Komunikasi Antar Manusia. (terjemahan: Agus Maulana). Jakarta: rofessional Books

Dyche, jill. (2011). The CRM handbook a business gride to a costumer relationship management. Addison Wesley

Dewi. Sutrisna.(2007). Komunikasi Bisnis, yogjakarta. C.V. Andi offset

Febrianingtyas, Media. (2013). Pengaruh Customer Relationship Management terhadap Kepuasan dan Loyalitas Nasabah. Universitas Brawijaya, Malang: Skripsi yang Tidak Dipublikasikan.

Griffin, Jill. 2008. Customer Loyalty How To Learn IT, How To Keep If. Mc. Grow.

Hurriyati, Ratih. 2008. Bauran Pemasaran dan Loyalitas Konsumen. Bandung: Penerbit CV. Alfabeta.

Jones, E. 2005. The Importance of Communication Quality In Services Thesis. USA: Florida State University, College of Communication.

Kaur, H. and Soch, H. (2012), "Validating antecedents of customer loyalty for Indian cell phone users". Vikalpa, Vol. 37 No. 4, pp. 47-61

Kotler dan Keller. 2007. Manajemen pemasaran Jilid 1 (12nd ed). Jakarta: PT Gelora Aksara Pratama. 
Kotler, P., \& Amstrong, G. (2008). Prinsip-Prinsip Pemasaran Jilid 2. Edisi 12. Jakarta: Penerbit Erlangga

Kottler, P., \& Keller, K. L. (2009). Marketing Management. 13th Ed. New Jersey: Upper Saddle River

Kotler, Philip and Kevin Lane Keller. 2009. Manajemen Pemasaran. Edisi 13 Jilid 1. Dialihbahasakan oleh Bob Sabran, MM. Jakarta: Erlangga.

Kotler, P dan Keller, K. (2009). Manajemen Pemasaran. Edisi 13. PT. Gelora Aksara Pratama, Jakarta.

Kotler, Philip and Kevin Lane Keller. 2009. Manajemen Pemasaran. Edisi 13 Jilid 1. Dialih bahasakan oleh Bob Sabran, MM. Jakarta: Erlangga

Kotler, Philip \& Gary Armstrong. 2012. Principles of Marketing, 14th edition. Pearson Education Limited, England

Kotler, P., \& Armstrong, G. (2011). Principles of Marketing (14th ed.). New Jersey: Prentice Hall

Lombard, M.R dan du Plessis, L. 2012. Customer Relationship Management (CRM) in a South African Service Environment: an Exploratory Study. African Journal of Marketing Management. Vol.4, Pp. 152-165.

Lovelock, Christopher \& Jochen Wirtz. 2011. Services Marketing. Peoples, Technology, Strategy. 7th edition. Pearson Education Limited, England.

Lupipyoadi, Rambat 2009. Manajemen Pemasaran Jasa. Jakarta: Salemba Empat

Rasyid, H.A. 2017. Pengaruh Kualitas Layanan Dan Pemanfaatan Teknologi Terhadap Kepuasan Dan Loyalitas Pelanggan Go-Jek. Jurnal Ecodemica, 1(2), 200-214.

Schiffman, L.G \& Kanuk, L.L. (2007). Consumer behavior (9th ed.). London: Prentice Hall

Sengupta, S. K., and Pusateri. 2000. Empirical Investigation of Key Account Salesperson Effectiveness. The Journal of Personal Selling and Sales Management. 20(4): 253.

Shim, T. A. (2003). Periklanan Promosi Aspek Tambahan Komunikasi Pemasaran Terpadu. EdisiKelima. Jakarta: Erlangga

Sheth, Parvatiyar, dan Shainesh. 2002. Customer relationship management: emerging concepts, tools and application. New Delhi: McGraw-Hill

Thaichon, P., Lobo, A. and Mitsis, A. (2014), “An empirical model of home internet services quality in Thailand", Asia Pacific Journal of Marketing and Logistics, Vol. 26 Iss 2 pp. $190-210$

Thaichon, P., Lobo, A. \& Mitsis, A. (2012), "Investigating the antecedents toloyalty of Internet service providers in Thailand: Developing a conceptual model". Paper presented at the Australian and New Zealand MarketingAcademy Conference, Adelaide, Australia 
Tjiptono, Fandy. 2005. Pemasaran Jasa. Malang: Bayu Media Publishing

Tjiptiono, F. (2007). Strategi Pemasaran. Yogyakarta: CV Andi Offset.

Tjiptono, Fandy. (2008). Strategi Pemasaran. Edisi Kedua. Yogyakarta: Andi Offse

Tjiptono, Fandydan Gregorius Chandra. 2008. Service Quality Dan Satifiction. Andi Offset.Yogyakarta. 